\title{
Assessing the degree of hydrologic stress due to climate change
}

\author{
R. J. Nathan ${ }^{1}$ - T. A. McMahon ${ }^{1}$ - M. C. Peel ${ }^{1}$ - A. Horne ${ }^{1}$
}

Received: 30 October 2018 / Accepted: 9 July 2019

(C) Springer Nature B.V. 2019

\section{Abstract}

Hydrologists are commonly involved in impact, adaption and vulnerability assessments for climate change projections. This paper presents a framework for how such assessments can better differentiate between the impacts of climate change and those of natural variability, an important differentiation as it relates to the vulnerability to water availability under change. The key concept involved is to characterize "hydrologic stress" relative to the range of behaviour encountered under baseline conditions, where the degree to which climate change causes the behaviour of a system to shift outside this baseline range provides a nondimensional measure of stress. The concept is applicable to any system that is subject to climate forcings, though the approach is applied here to a range of examples illustrative of many environmental and engineering applications. These include hydrologic systems that are dependent on the frequency of flows above or below selected thresholds, those that are dominated by storage and those which are sensitive to the sequencing of selected flow components. The analyses illustrate that systems designed or adapted to accommodate high variability are less stressed by a given magnitude of climate impacts than those operating under more uniform conditions. The metrics characterize hydrologic stress in a manner that can facilitate comparison across different regions, or across different assets within a region. Adoption of the approach requires reliance on the use of climate ensembles that represent aleatory uncertainty under both baseline and impacted conditions, and this has implications for how the outputs of climate models are provided and utilized.

A considerable body of research has been published on the projected hydrological changes associated with a warming climate (Seneviratne et al. 2012; Jiménez-Cisneros et al. 2014). These projections have been used to examine large regional or global risks to water resource systems (Zheng et al. 2018; Vorosmarty and Salisbury 2000), and to investigate in detail the risks for a particular region (Prudhomme et al. 2010; Brown et al. 2012). Within such studies,

\section{R. J. Nathan}

rory.nathan@unimelb.edu.au 
the impacts of climate change on hydrology are commonly characterized as changes in the long-term behaviour of selected components of the water cycle (Ekström et al. 2018). These impacts have included changes in the mean or seasonality of runoff (Gosling et al., 2011; Sheffield et al., 2015), average recharge to groundwater (Döll 2009), water scarcity (Schewe et al. 2014) and specific hydrologic indicators of flow regime (Arnell and Gosling 2013). Changes in average flow conditions have been used to assess impacts on engineering systems developed for water supply (Arnell et al. 2011) and hydropower (Beyene et al. 2010). Impacts on long-term hydroclimatic averages have also been used to assess projected changes in mean water levels in freshwater wetlands (Fay et al. 2016), ecologically relevant flow components (Döll and Zhang 2010), threats to freshwater fish health (Van Vliet et al. 2013), vulnerability of freshwater ecosystems (Markovic et al. 2017) and mean change in the richness of freshwater species (Mantyka-pringle et al. 2014). Increasingly, efforts are made to assess impacts on hydrologic extremes in terms of the probability of occurrence of a given event, or in terms of the probability of exceedance above some threshold (Klein-Tank et al. 2009).

Assessing impacts in terms of changes in the statistics of long-term behaviour is readily presented and understood, but such measures are not well suited to assessing the significance of the impacts in a manner that accommodates expected differences due to climatology, physical attributes and system-specific characteristics. For example, while a global map of projected changes in the long-term behaviour of a given measure is readily perceived, the significance of the impacts at different locations depends heavily on the variability of system performance. Furthermore, the temporal resolution of most long-term studies is not sufficient to capture the impact of variability over shorter periods to which the life histories of environmental systems are often intimately linked (Chapman et al. 2014). Similarly, as discussed in the following section, there are many systems in the built environment which are sensitive to periods that are considerably shorter than the length of baseline periods used for climate impacts studies. Hydrologic systems are inherently non-linear - that is, the relation between cause (e.g. input) and effect (e.g. output) is not proportional—and this is evident at almost all spatial and temporal scales (Sivakumar and Singh 2012). The effects of non-linearity can be tremendous, and even small changes in the climatic inputs may result in large changes in the outputs (Sivakumar and Singh 2012). Without understanding how the variability of system inputs impact on the outputs, it is difficult to assess whether a given change in a performance metric is of concern or not.

In this paper, we develop an approach that facilitates comparison of hydrologic performance of different systems under current and future projected climate conditions. The approach is relevant to the assessment of hydrologic systems that vary in response to climatic variations in temperature, rainfall and evaporation over various time scales. Such systems include services based on freshwater resources, terrestrial and freshwater ecosystems, coastal and marine systems and food security and production systems (Field et al. 2014). The performance of these systems may vary markedly with climatic variability, and thus assessments of climate change need to give explicit account of this natural variability (Vorosmarty et al., 2010; Chapman et al. 2014; Wang et al. 2018a, 2018b; Ekström et al. 2018). We present several examples that illustrate the hydrologic performance of different natural and engineered systems, where the underlying principles are considered relevant to impact assessments on a wide range of physical and biological systems.

The process of developing metrics related to system performance is a common requirement for methods designed to inform decision making. For example, the first step involved in "scenario neutral" and "decision scaling" approaches (Prudhomme et al. 2010; Brown et al. 
2012) involves the development of performance metrics, which are then considered in later

steps that require the evaluation of system performance under a range of climate scenarios.

Similarly, a necessary component of alternative approaches based on "storylines" and "narra-

tives" of plausible future climates (Shepherd et al. 2018) is the need to raise risk awareness by

framing risks in an event-orientated rather than probabilistic manner. While this paper does not

address the issues involved in how hydrologic information is used in decision making, the

development of a metric that assists people perceive and respond to risks is an integral component of such methods.

We first describe a generic measure of system stress that can be used to differentiate

(GCMs) can be provided to better suit the need of practicing hydrologists, and this is discussed in Section 4.

The ideas discussed in this paper are tempered by the experience of the authors who have been involved in surface runoff hydrology and water resources system modelling over several decades. The authors are not climate scientists, but rather are practice-orientated applied researchers and engineers who are engaged in the mining of climate science literature to assess the impacts of climate change on hydrological systems.

\section{A framework for assessing system stress}

Many studies have been undertaken over the past 30 years assessing the impact of climate change on hydrologic systems. The linking of climate change modelling to catchment-scale climate scenarios involves considerable complexity, including ensuring that downscaled climate data are not biased with respect to magnitude and variance, and that the derived scenarios give due account to the nature of the projected changes and the possible influence of non-stationarity in the observed data sets (Fowler et al. 2007; Fu et al. 2013). There are thus a variety of ways that such studies can be undertaken, but in concept all such investigations are similar in that they involve the comparison of outputs from hydrologic models run with inputs representative of "baseline" and "future" climatic conditions.

Our proposed approach to assessing the hydrologic stress of any system under climate change is illustrated in Fig. 1. It represents a generalization of approaches that have been used in earlier studies focused on assessing the relative impacts of natural variability and climate change. The approach consists of four major steps involving (1) the identification of a period that is characteristic of system stress, (2) the derivation of an ensemble of hydroclimatic sequences representative of current and future conditions, (3) the simulation of system performance for each member of the ensemble and (4) the evaluation of hydrological stress through comparison of the distribution of performance metrics. Each of these steps are discussed below.

The first aspect of key importance is the typical time period-here termed "characteristic 


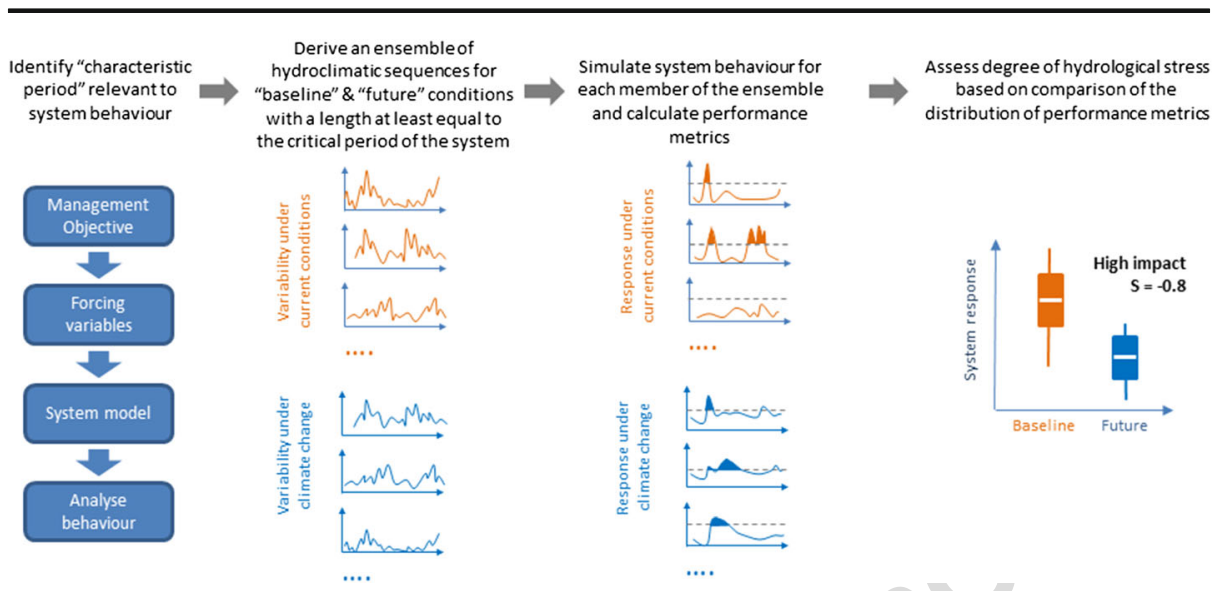

Fig. 1 Approach used to calculate the stress metric resulting from a projected level of climate change

droughts lasting a few weeks or months, whereas a system with a storage capacity able to impound runoff over two or more years will be sensitive to multi-year droughts. This concept of characteristic period can easily be extended to the performance of many types of system. For example, when considering biological systems, it is appropriate to consider the period over which a species may be especially sensitive to the occurrence - or absence - of climatic conditions that are essential to its health. Thus, food crops are dependent on the sequence of rainfall and evaporation conditions over the growing season, whereas Wang et al. 2018a, bfound that the condition of a riparian forest was dependent on the sequence of flows over a 10 - to 20 -year period. The relevant period for some short-lived fish might be 1 year while that for long-lived fish, or riparian wetland systems, may be 15 years or longer (Bond et al. 2017). The concept of characteristic period also has a financial analogy, for instance investments in hydropower plant will often be based on payback periods that are less than 10 years (Jackson and Cardenas-Lailhacar 2010).

An illustration of the range of different characteristic periods for common hydrological applications is provided in Fig. 2. The purpose of this figure is to illustrate the notional range representative of different hydrological applications commonly considered: the extent of different examples is only indicative of the relative differences between applications, and the precise limits are merely provided to qualitatively illustrate the differences involved. The different applications are plotted against the typical time step required for simulation of system performance. The range of simulation time steps has implications for the challenges involved in accommodating the temporal and spatial scales of Global Climate Model (GCM) outputs in hydrological modelling, and this is discussed in Section 4.

The second step required to assess system stress due to climate change is the derivation of hydroclimatic ensembles that are representative of baseline and future conditions. The length of the climate ensembles over which the simulations are undertaken is selected to be at least equivalent to the notional characteristic period of the system, where the objective is to adopt enough ensembles to adequately define the distribution of performance metrics. Such sequences may be derived by simply dividing the gauged (or synthetically generated) record into sub-series of equal length. It would be expected that there is some uncertainty regarding the length of the characteristic period relevant to system performance, indeed the length of period which causes system failure is inherently subject to some level of (irreducible) aleatory 
uncertainty as the nature of the sequences vary from event to event. However, our main interest

is to assess the shift in outcomes associated with alternative climate scenarios and thus it is

only necessary to adopt a simulation period that yields a range of outcomes linked to system performance. The length of the characteristic period does have an influence on the methods that can be used. If the characteristic period is long relative to the length of available record, then it will be necessary to use stochastic data generation techniques to derive the ensembles. If it is short, then a sufficient number of sequences could be obtained by sampling from a single record representative of baseline conditions. The notional range of application of these two approaches is shown in Fig. 2, where it is seen that stochastic methods are more relevant to systems with long characteristic periods, while simpler methods based on sampling subperiods within the observed record are more relevant to systems with short characteristic periods. The issues involved in deriving suitable time series for climate impact assessment are further discussed in Section 5.

The third step involves use of the climate ensembles (current and climate change conditions) to derive distributions of system performance over a duration equivalent to the notional characteristic period for the system. While presentation of impacts in terms of a change in frequency or event magnitude provides an unambiguous measure of severity, such measures are not necessarily useful to operators or stakeholders of a hydrological system. Perhaps the most common hydrological example that illustrates this difficulty is the nature of the link between mean annual runoff and water supply risk. A reduction in mean annual runoff of $10 \%$ may have negligible implications for the reliability of a water supply system which extracts only $5 \%$ of the average flows via a diversion weir. The significance of the impact will increase as the proportion of consumptive demand increases, but the degree of severity is heavily dependent on the storage capacity of the system and the natural variability of inflows. Two 183 water supplies with different storage attributes subject to the same hydroclimatology may

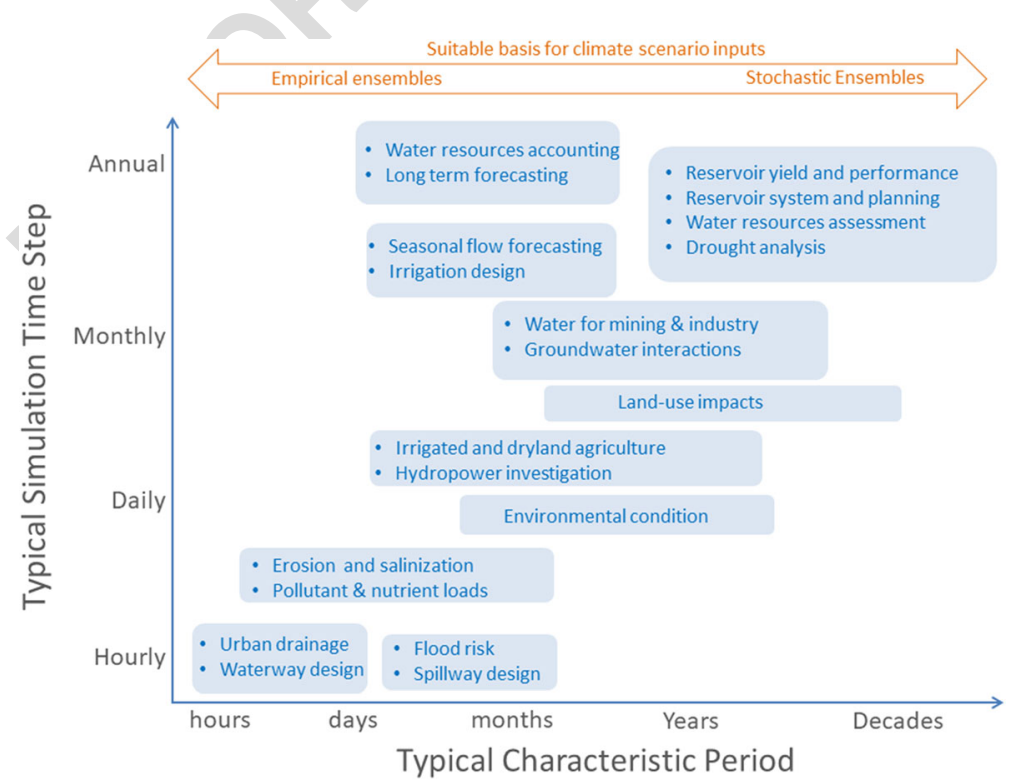

Fig. 2 Notional range of simulation time-step and characteristic period for a range of hydrological applications, and indicative nature of applicable simulation methods 
respond very differently to the same set of climate projections. The relationship between these factors and the reliability of supply is explored in the following section, but suffice to state here that it is not possible to draw any inferences about the impact of climate change on system performance without an understanding of system attributes.

Once the distribution of performance metrics has been obtained from analysis of system behaviour over the scenario ensembles, then the degree of hydrological stress may be characterized by the degree of overlap between current (baseline) and scenario conditions. This is illustrated in the right-hand panel of Fig. 1. The distribution of outcomes under current conditions defines the range of behaviour that the system currently exhibits. The distribution of outcomes represents the uncertainty in system performance due to natural variability under a set of baseline conditions. In the built environment it might be expected that this range of outcomes corresponds to performance levels that the system has been designed to accommodate, and in the natural environment it might be expected that this represents the range of environmental conditions that a species has adapted to. The distribution corresponding to a future climate indicates the change in behaviour resulting from a projected change in climate conditions.

The shift in the location and scale of these distributions reflects the impacts of climate over a time scale represented by the characteristic period of most importance to the system of interest. If the range of future behaviour lies largely within the range encountered under baseline conditions, then it can be concluded that the additional stress on the system due to climate change is low. Conversely, if the range of behaviour under projected future conditions lies mostly outside the range that the system is accustomed to, then the degree of stress is high. The degree of shift in the central tendency of the distributions could provide a quantitative measure of system stress. For example, the degree of shift in the median response could be represented non-dimensionally as a proportion of the standard deviation of performance metrics obtained under baseline conditions. Alternatively, a measure could be developed whereby the degree of shift is represented in terms of the proportion of overlap between the distributions of both scenarios. The frequency distributions of performance metrics are likely to be non-normal and zero-bounded, and thus it is reasonable to derive a stress metric using a simple non-parametric index. If $B_{i}$ and $F_{i}$ denote the relative cumulative frequencies of achieving selected performance outcomes under baseline $(B)$ and future $(F)$ conditions, then a stress metric may be computed as follows:

$$
S=\operatorname{sgn}\left(M_{\mathrm{B}}-M_{\mathrm{F}}\right)\left(\left(\sum_{i=O_{\min }}^{O_{\max }} \min \left\{\left(B_{i+1}-B_{i}\right),\left(F_{i+1}-F_{i}\right)\right\}\right)-1\right)
$$

where $M_{\mathrm{B}}$ and $M_{\mathrm{F}}$ denote the median performance under baseline and future conditions, respectively, and $O_{\min }$ and $O_{\max }$, denote the minimum and maximum levels of performance under both sets of conditions. An example calculation of the metric is provided in the righthand panel of Fig. 1. The equation provides a simple non-parametric method to calculate the area under the overlapping portions of the two distributions. (We note the approach of comparing two distributions was adopted by Perkins et al. (2007) in their study of the performance of AR4 climate models.) The calculation of the stress metric is undertaken using simple empirical distribution functions as it is assumed that the number of simulations available to compute performance metrics will generally be limited due to the computational effort involved. The equation can be evaluated over any number of intervals between the selected limits, but 10 or so intervals should be sufficient to capture the degree of overlap involved. The right hand terms in Eq. 1 yield a value that is constrained between 0 and 1 (as the degree of overlap is expressed in terms of the shift in relative frequency, or notional 
probability), and the sgn() term merely ensures that the metric is positive if the performance metric is in general higher than baseline conditions, and the metric is negative if the reverse is true. Thus, a metric value of -1 indicates that the entire range of future outcomes lies wholly below the range of baseline conditions, and a metric value of +1 indicates that the range of future conditions lies wholly above baseline behaviour. A metric near zero indicates that the behaviour under future conditions is very similar to baseline conditions. The stress metric values can be assigned objective qualitative descriptors, where for example a value within the range \pm 0.3 could be regarded as "low stress," a value of \pm 0.7 as "medium stress" and larger absolute values could be considered "high stress."

Since the basis of this non-dimensional metric is tied to the range of variation found under baseline conditions then any assessment of stress is directly comparable across regions of differing hydroclimatology. Thus, for example, a manager of a portfolio of assets could use the quantitative values of the metric to help prioritize investment effort on those systems that are most stressed (and whose consequences of failure are most costly). In developing Eq. 1, if one wished to test whether the baseline and future terms in Eq. 1 were statistically different, a Mann-Whitney test could be used to estimate whether the data were drawn from different populations. If the spread and shape of the data were similar, one could extend the test to whether the medians were statistically different (Hart 2001). That said, we note the concerns of Amrhein et al. (2019) regarding the desirability of "abandoning" tests of statistical significance, and consider that inferences regarding the impacts of climate change may be better served by understanding the practical differences in the degree of overlap between the derived frequency distributions (which is the basis of Eq. 1). Examples illustrating application of this approach to systems varying markedly in their natural variability are provided in the following section.

\section{Application of hydrologic stress measures}

\subsection{Characteristics of catchments of differing variability}

To illustrate how the assessment of hydrologic stress varies with variability, a selection of four catchments was obtained from the data set compiled by Peel et al. (2010). The four catchments are Roseway at Lower Ohio (Canada), Gloma at Knappom (Norway), Tercero at Embalse (Argentina) and Wimmera River at Glynwylln (Australia).

The catchments were selected somewhat arbitrarily to represent a range of streamflow behaviour found globally. Figure 3 provides summary statistics related to catchment area, the number of years of record, mean annual flow and the variability (measured as the coefficient of variation) of annual and monthly flows $\left(\mathrm{CV}_{\mathrm{a}}, \mathrm{CV}_{\mathrm{m}}\right)$. The smallest catchment (Roseway River) has a catchment area of $495 \mathrm{~km}^{2}$ and the largest (Tercero River at Embalse) has an area of $3300 \mathrm{~km}^{2}$. All sites have around 70 years of record. The mean annual flows (represented as a depth per unit area to facilitate comparison) span a wide range, from $1022 \mathrm{~mm}$ for the Roseway River down to $42 \mathrm{~mm}$ for the Wimmera River. The different rivers also exhibit a wide range of variability, where the Wimmera River is almost six times more variable than the Roseway River (i.e. an annual $\mathrm{CV}_{\mathrm{a}}$ of 0.98 compared to 0.17 ).

Figure 3 also illustrates the differences in the pattern and occurrence of low flow periods associated with different degrees of flow variability, as indicated by the coefficient of variation of monthly flows. It is seen that low flow periods in rivers of low variability (e.g. Roseway and 


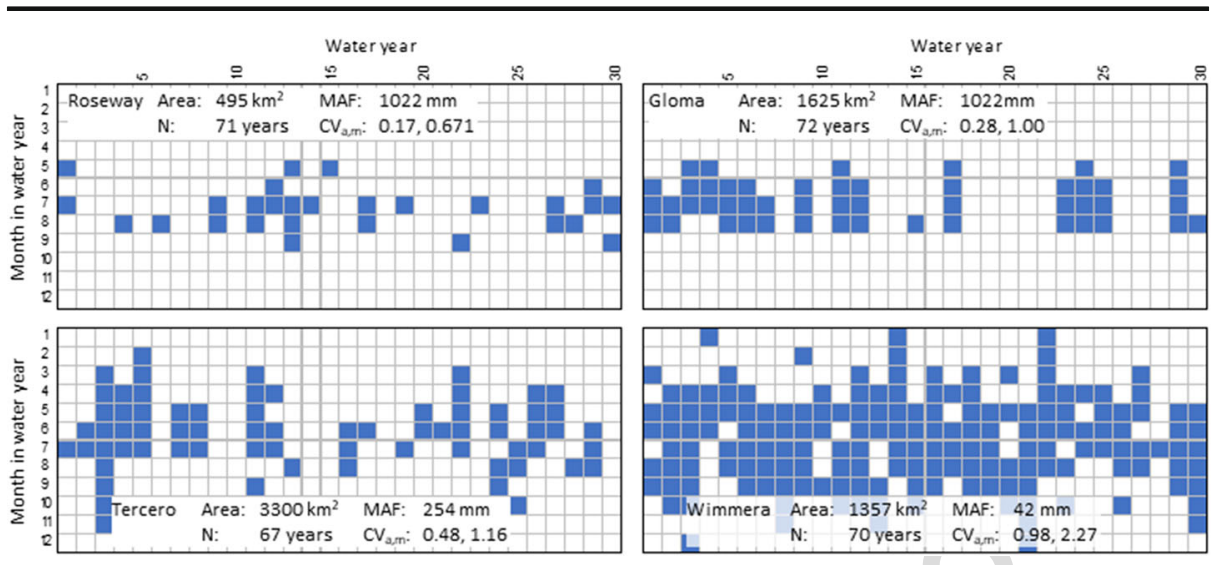

Fig. 3 Illustration of the influence of variability on low flows, where the shaded cells indicate monthly flows which are less than $20 \%$ of the mean monthly flow. Each grid cell represents flow behaviour in a particular month of the year over a 30-year period. Those systems with low variability (Roseway and Gloma rivers) have more predictable low flow period, while systems with higher variability (Wimmera river) can have less predictable low flow periods occurring at any time of year and lasting a single month up to many months

Gloma) occur in a reasonably predictable fashion: such events tend to occur in a specific season, and their frequency of occurrence lies within a narrow range of behaviours. In contrast, low flow periods in a highly variable river (e.g. the Wimmera River) can occur in any month of the year and may last just a single month or extend over many months. This difference in variability has implications for many engineering and environmental systems. For example, the operation of a water supply or treatment system often needs to respond to specific low flow trigger levels, such as curtailing effluent discharges until dilution flows return to sufficient levels, or the provision of regulated releases to satisfy minimum operational flow requirements. It is also common to specify low flow thresholds which need to be maintained to satisfy environmental requirements (e.g. Filipek et al. 1987).

The nature of the impact of climate changes on the selected catchments is illustrated using three types of examples that in generic terms span a wide range of hydrological applications. The examples consider the degree of stress arising from a changed climate on systems that are dependent on the frequency of flows above or below selected thresholds, on systems dominated by storage, and on systems which are sensitive to the sequencing of selected flow components. These examples are provided in the following sections.

\subsection{Flow threshold behaviour}

The performance of many hydrologic systems depends on the frequency of time that flows are above or below some given threshold. For example, gravity diversion flows may cease when flows fall below a particular weir flow threshold, or conversely, they may only occur when flows are above a particular flow threshold. Environmental systems also adapt to a particular flow regime, where connectivity between river reaches may cease when flows fall below critical thresholds, or conversely riparian wetlands may depend on flows exceeding bankfull discharge with a given frequency to preserve ecological function. Thus, examination of changes to hydrologic stress under climate change or some other stressor often involves the 
To illustrate how hydrologic stress can be characterized meaningfully, data sets were prepared for each of the four selected catchments to represent current (or baseline) and future (or changed) conditions. A characteristic period of 10 years is selected for illustration purposes, as this represents a short-term planning horizon over which economic performance might be usefully assessed, or a period over which it would be useful to assess changes to the population dynamics or health of an environmental system. To this end, statistics relating to the mean, standard deviation and auto-correlation of the annual data were used to stochastically generate 100 replicates of length 70 years, which is close to the length of the historic record for each site. A first order Markov model incorporating a Box-Cox transformation was used to generate the data at an annual time step, and the annual values were disaggregated to a monthly time series by the method of fragments (McMahon and Mein 1986). Data sets representing future conditions were obtained using an identical process, but it was assumed that mean annual flows were $20 \%$ lower. Obviously if the characteristic period of interest is short compared to the length of the historic record then sufficient replicates representative of the aleatory uncertainty involved could be obtained by simply dividing the historic data set into nonoverlapping periods of the required duration, but the use of stochastic data generation approaches provides more flexibility and ensures the comparisons are not confounded by issues of non-stationarity.

The differences in hydrologic stress arising from a $20 \%$ reduction in mean annual flows are shown in Fig. 4. The sites are arranged in order of increasing variability, with Roseway River $\left(\mathrm{CV}_{\mathrm{a}}=0.17\right)$ being the least variable stream and Wimmera River $\left(\mathrm{CV}_{\mathrm{a}}=0.98\right)$ the most variable. The left-hand panel summarizes the frequency of months where flow conditions fall below $30 \%$ of the current mean monthly flow in each 10 -year sequence. The distribution of outcomes is evaluated over each 70-year period and the boxplots represent the median of the selected percentiles based on 100 replicates. The right-hand panel shows the same information for the frequency of months in each 10-year sequence where flows are above a threshold that is twice the magnitude of the current mean monthly flow. It is seen that the range of outcomes under current conditions increases from left to right, which indicates that - as expected - the variability in the frequency of events below/above the selected thresholds increases in a consistent manner with the variability of annual streamflows. The frequency range varies non-linearly with the annual coefficient of variation; for example, the range in the frequency of threshold occurrences in the Wimmera River is about three times greater than that in the Roseway River, though annual streamflows are over 20 times higher in the Roseway River.
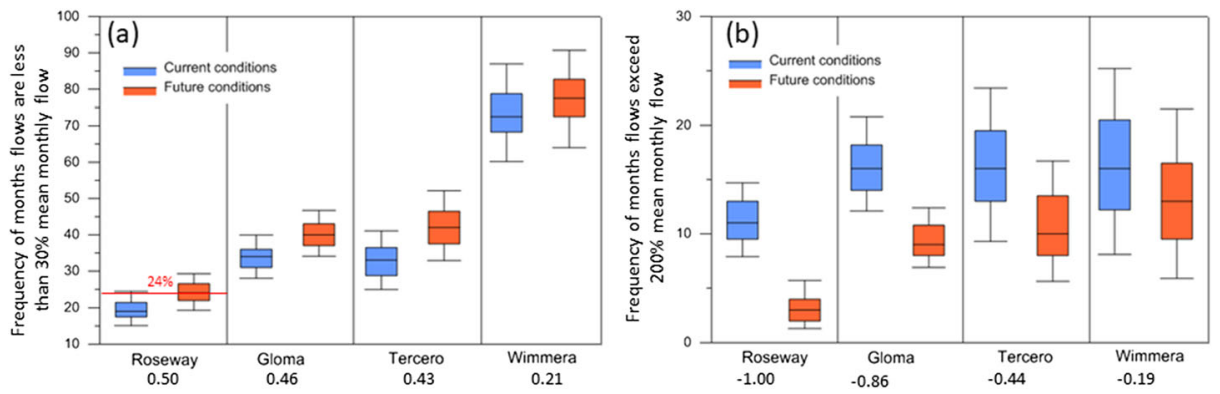

Fig. 4 Impact of a $20 \%$ reduction in mean annual flows on the proportion of months a below a threshold of $30 \%$ of the current mean monthly flow and $\mathbf{b}$ above a threshold of $200 \%$ of the current mean monthly flow. The boxplots represent the $5 \% / 95 \%, 25 \% / 75 \%$ and the median frequency of behaviour, and the figures below the river names indicate the associated stress score of the impact 
Of particular interest here is the nature of the relative impacts on outcomes. Overall, it is observed that the degree of overlap in the distribution of outcomes is inversely proportional to the annual variability in streamflows; the difference in the degree of overlap of outcomes in Roseway River is large compared to the Wimmera River, which indicates that the impact of climate change on Roseway River (which exhibits low natural variability) is greater than that found on the Wimmera River, which is more highly variable. With regard to the low flow behaviour in Roseway River illustrated in Fig. 4a, our analysis of the 100 replicates, each 70 years in length, suggests that there is only a $5 \%$ chance (i.e. in 5 of the 100 replicates) in any 10 -year period that low flow conditions (adopted as flows below 30\% of current mean monthly flows in this example) will occur $24 \%$ of the time; in other words, under current conditions it is very unlikely that low flows will occur as often as 1 month in around every four over a 10-year period.

In contrast, the degree of impact in the Wimmera River is considerably less: the median frequency of low flow events projected to occur in the future lies within the central $50 \%$ range of behaviour found under current conditions. This difference in impact is represented by the difference in the stress metric values computed using Eq. 1. It may be seen from the metrics shown in Fig. 4a that a $20 \%$ reduction in mean annual flows represents a stress of 0.5 in Roseway River, which is around twice that projected to occur in the Wimmera River. In terms of impacts on high flows, the degree of overlap in the distribution of outcomes in the Roseway River is appreciably worse than in the Wimmera River, and this is reflected in the associated stress values $(-1.0$ compared to -0.19 , Fig. 4 b). In general, it is seen that the stress values vary reasonably consistently with flow variability. Systems which have adapted to highly variable flow conditions have lower stress values than those with more uniform flow conditions. That is, it may be expected that highly variable systems more easily accommodate a given level of change than systems that have adapted to conditions of lower variability. The stress metric can be viewed as a non-dimensional indicator of the degree of hydrologic stress that would be useful when comparing the resilience of different systems, or for the ranking of threats across a portfolio of assets.

\subsection{Storage behaviour}

Assessing the impacts of change on water resource security is of vital interest as there is good evidence to indicate climate change is projected to reduce surface water resources in most dry subtropical regions (Jiménez-Cisneros et al. 2014). To illustrate how hydrologic stress on storage-dominated systems is dependent on the degree of natural variability, simulations of water supply behaviour were undertaken for each of the four study catchments. The same stochastic representation of current streamflows was used as described in the previous section, though here the influence of climate change was represented by a reduction in mean monthly flows of only $10 \%$. Compared to the previous example, there is a greater need to adopt stochastic data techniques to assess impacts on storage yield reliability as the simulation analysis of multiple independent sequences from the historic record. In this example, stochastic replicates are used to characterize the uncertainty in system performance over sequences that are similar to the length of available data.

Water supply security was assessed using a monthly time step where the capacity of the storage was assumed equal to the historic mean annual flow. Average monthly estimates of rainfall, potential evaporation and temperature were obtained from Hijmans et al. (1978) and Zomer et al. (2008) and these data were used to estimate monthly average demands and net 
evaporation from the reservoir surface. The pattern of monthly demands was represented by a

fixed and variable component, where the latter was assumed to vary proportionally with temperature. For illustration purposes the security of supply is represented by the proportion of months in the simulation period where storage contents fall below $10 \%$ of the storage capacity. A common baseline level of performance was achieved by adopting an annual average demand that yielded a probability of failure of $10 \%$ under current climate conditions (i.e., a demand which causes stored volume to fall below $10 \%$ of the storage capacity in $10 \%$ of the months). Defining failure in this fashion is a simplification of the manner in which demand would be restricted to achieve required performance targets, but the adopted combination of storage level and failure probability provides a useful indicator of water supply risks for illustration purposes.

Figure 5 summarizes the impacts of climate change on supply reliability for the four selected catchments. The boxplots represent the distribution of results obtained from 100 replicates of 70-year simulations, and the study catchments are again arranged (from left to right) in order of increasing natural variability. It is observed that the median reliability for all supplies under current climate conditions is $10 \%$ (which is a consequence of the adopted level of demands), and that there is a slight tendency for the range of performance to increase with increasing natural variability. The main point to note is that the degree of hydrologic stress associated with a $10 \%$ reduction in mean annual flow decreases markedly with increasing natural variability. The range of system performance under climate change in Roseway River lies entirely outside the range of behaviour observed under current climatic conditions, and thus the stress value for this impact is 1.0. The stress values decrease with increasing variability, and it is seen that the range of performance under climate change in the Wimmera River largely overlaps with the range of performance under current climate conditions. That is, for an equivalent projected degree of climate change, the hydrologic stress experienced by the Roseway system is markedly greater than that exhibited by the Wimmera system. In absolute terms the water supply volumes provided by these systems decrease with increasing

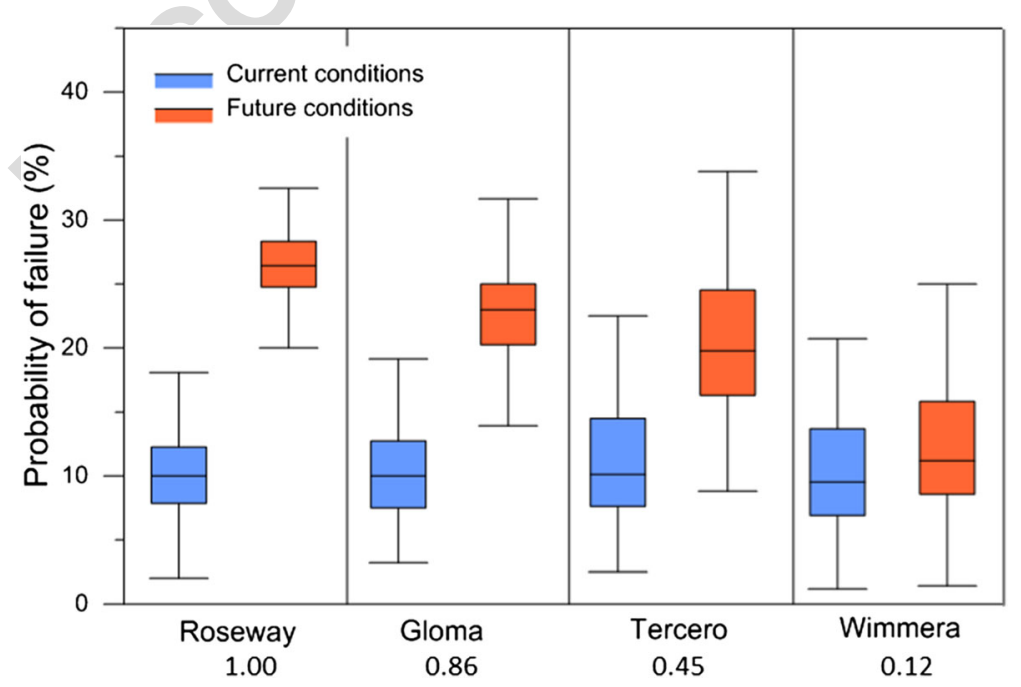

Fig. 5 Impact of a $10 \%$ reduction in mean annual flows on the reliability of water supply yield. The boxplots represent the $5 \% / 95 \%, 25 \% / 75 \%$ and the median likelihood of failure based on 100 replicates each of 70 years duration, and the figures below the river names indicate the associated stress score of the impact 
variability - the annual volume of water supplied by the Roseway system with a failure probability of $10 \%$ under current climate conditions (as defined above) is around twice that provided by the Wimmera system - but given that hydrologic systems are designed to provide a given level of performance, it is the degree of hydrologic stress associated with projected changes that is of most interest to stakeholders. As illustrated by the foregoing analysis of flow occurrences above or below selected thresholds, the degree of stress on the security of supply associated with a given level of climate change is greater in rivers with uniform flow regimes than those that are highly variable.

\subsection{Flow sequence behaviour}

The performances of many environmental systems are heavily dependent on changes to the four rivers, whose health is dependent on the frequency and occurrence of an autumn spawning pulse (Horne et al. submitted). The state of this hypothetical species improves or declines depending on the number of spawning events in recent years, where the health of the population is represented by four categories (good, average, poor and critical). A spawning event is assumed to occur if the monthly flow for any of the autumn months is greater than a fixed fraction of average flows for that month under natural conditions. It is assumed that their condition transitions from good to critical over 3 years if there are no spawning events, and it takes 3 years to recover with good spawning events. The health of the fish is maintained whenever at least one spawning event occurs in each year. As the variability of streamflow sequences in each river differs, the actual threshold adopted for each river is selected to ensure that the fish is in either poor or critical condition in $20 \%$ of years under current climatic conditions. As before, the analysis is undertaken using stochastically generated data, where the health of the fish population is evaluated over 15-year periods which is the assumed expected life span of the fish.

The simulation results are shown in Fig. 6. The median state of the fish population being in poor or critical condition under current climate is the same for all rivers, which of course reflects the choice of threshold adopted to represent a spawning event. The degree of stress that the fish population experience due to climate change heavily depends on the natural variability of the system. While the future climate in the four rivers is assumed to decrease by the same degree ( $20 \%$ of the mean annual flow), the proportion of time that the fish are deemed to be in poor or critical condition increases inversely with streamflow variability. Thus, in the Roseway River, there is projected to be a material shift in the proportion of time that the fish population is in typically poor or critical condition, and hence the degree of stress suffered by the fish is characterized by a stress value of 0.42 . Conversely, in the Wimmera River, the degree of stress under climate change is more similar to what is found under current conditions, and hence the stress value is lower (0.19).

\section{Use of GCMs to assess hydrologic stress}

The outputs of Global Climate Models (GCMs) have been widely used by hydrologists to 


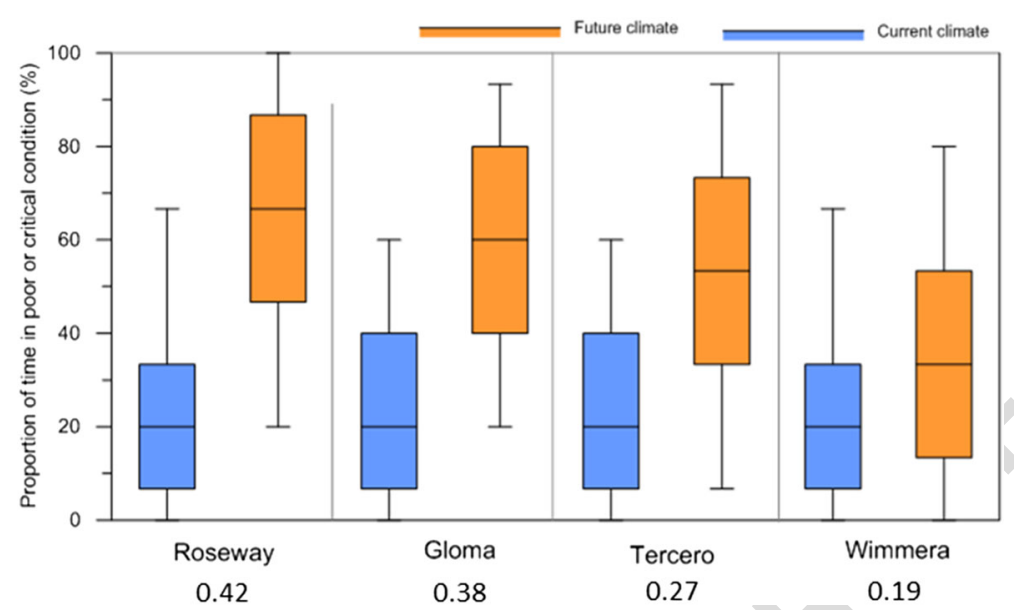

Fig. 6 Illustrative example of the implications of variability for the relative impact of climate change on fish health. The boxplots show the proportion of time the fictitious fish species is in poor or critical condition over a 15-year period under both current and future climate. The boxplots represent the upper and lower 5 and $25 \%$ exceedance percentiles, and the median, and the figures below the river names indicate the associated stress score of the impact

best estimated from multiple GCMs (e.g. Gleckler et al. 2008), and accordingly it is common to use multi-model ensembles to derive estimates of hydrological impacts at the catchmentscale (Gosling et al. 2016). However, while such multi-model ensembles provide valuable information on the epistemic uncertainty involved, they do not allow the separate consideration of the impacts of natural variability and climate change. That is, the range of results obtained from different GCMs provides insights on the uncertainties related to model structure and parameterization; they shed little light on the aleatory uncertainties associated with the random nature of natural processes and internal variability in the climate system (Ekström et al. 2015).

The use of climate model projections in a manner that allows consideration of natural variability presents particular challenges for hydrologists. While GCM projections from multiple models are readily accessible (e.g. CSIRO, 2015; KNMI Climate Explorer; ESGF CMIP archive; Taylor et al. 2012; Eyring et al. 2016) the number of ensemble members from each GCM available to represent natural (internal) variability is limited; the minimum number of runs requested for models in the core CMIP5 experiments was three (Taylor et al. 2012), and this is the same number requested in the current CMIP6 design (Eyring et al. 2016). The provision of only three ensemble members per GCM is not sufficient to characterize the uncertainty in behaviour over a given simulation period, and stochastic alternatives for approximating natural uncertainty have been proposed (e.g., Peel et al. 2015). A minimum of perhaps 20 ensemble members would be appropriate, though it is recognized that the enormous computational costs involved are an impediment. The recent availability of ensembles of initialised decadal predictions (Yeager et al. (2018) is an example of a valuable resource that allows the assessment of internal model variability and the influence of initialisation on projections.

Regardless of the number of ensemble members, such projections need to be downscaled in some fashion for use in impact and stress assessments. There are many different ways in which GCM outputs can be downscaled for local climate change impact assessment, but two simple approaches commonly used by hydrologists are the constant and quantile scaling methods (the 
former approach is also referred to as "change factor" and "delta change" method). The merits and implications of different downscaling approaches have been investigated by a number of authors (e.g. Fowler et al. 2007; Ekström et al. 2015; Zhao et al. 2017), and it has been shown (e.g. Teutschbein et al. 2011; Wang et al. 2017) that the choice of downscaling methods can be of similar importance to that of GCMs in hydrological impact studies. However, in the context of this paper, the main limitation of the commonly used constant and scaling methods is that the future climatic sequences are assumed to be largely the same as historical. That is, while the application of constant or quantile-based factors to annual or monthly climate data will change the relative magnitudes over different sub-periods, the overall pattern and sequencing of future dry and wet periods over all time scales is the same. This means that any projected changes to the intensity and frequency of wet and dry periods (or associated projections on changes to the frequency of wet days) cannot be assessed (Fowler et al. 2007). Even small differences in sequencing can have a material impact on the assessment of hydrologic stress (Wang et al. 2018a, 2018b), thus the use of simple change factor methods is not well suited to characterizing hydrologic stress under projected changes.

Given the dependence of many hydrological systems to temporal variability and sequencing, then it is desirable to use more complex statistical downscaling techniques or outputs from dynamical downscaling methods (Ekström et al. 2015). Statistical downscaling techniques are attractive to hydrologists as the broad nature of the methods involved are computationally efficient and are based on standard statistical procedures; however, the methods assume nonstationarity in the predictor-predictand relationship, climate feedbacks are not included, and the skill of the approach varies with scale, region, and season (Fowler et al. 2007). In contrast, applied researchers involved in impact and stress assessments do not have the means to undertake dynamical downscaling procedures. While initiatives such as the CORDEX framework aim to provide credible Regional Climate Model (RCM) projections in a coordinated manner (Giorgi and Gutowski 2015), the nature and availability of dynamically downscaled products varies with region and the required data are hard to find and process (Rössler et al. 2017).

Rössler et al. (2017) discusses the tension between impact modellers and societal users who "want everything", and climate scientists who want to ensure that the data provided has the highest reliability. It is interesting that in the survey results of stakeholder needs discussed by Rössler et al. (2017), Swart et al. (2017) and Hewitt et al. (2013), no specific mention is made of the needs of users for ensembles to assess uncertainty arising from natural variability. The large majority of users surveyed by Rössler et al. (2017) were from the water sector, where the most common variables identified were for the provision of temperature and precipitation at spatial scales of $1 \mathrm{~km}^{2}$ and smaller, and temporal scales of daily or shorter. As summarized in Fig. 2, these scales are relevant to a sizeable proportion of typical hydrological assessments, where hydrological stress could be calculated using Eq. 1 based on independent samples taken from a single time series that has been factored in some simple manner to represent future climatic conditions. However, for other applications involving longer characteristic periods then it would be necessary to analyse ensembles from more sophisticated downscaling procedures.

\section{Conclusions}

Considerable effort is being given to the undertaking of climate impact, adaption and vulnerglobal warming. The simple approach presented here for characterizing hydrologic stress is 
based on the degree to which behaviour under impacted conditions is similar to the range of behaviour found under baseline conditions. A non-dimensional stress metric is presented which quantifies the degree of stress in non-dimensional terms. If the range of behaviour under impacted conditions lies largely outside that observed under baseline conditions, then the system is assessed as being highly stressed; if it lies well within the range of behaviour then the system is not stressed.

An important element of the approach is that behaviour is evaluated over a time period that is characteristic to the performance of the system. This "characteristic period" may be short or long compared to the period of available record. If short, then a range of behaviour can be assessed by evaluating performance metrics over samples selected from the entire time series; if long, then it will be necessary to employ stochastic procedures to generate multiple replicates that preserve the same statistical properties of the original time series. These series are perturbed to reflect the impacts of climate change, and the degree of stress is evaluated with reference to the difference performance metrics obtained from the analysis of both time series.

The degree of hydrologic stress is evaluated for four rivers that notionally span the range of natural variability found globally, using performance metrics related to the frequency of flows above or below selected thresholds, on the reliability of systems dominated by storage, and on systems which are sensitive to the sequencing of selected flow components. The examples illustrate how characterizing climate impacts in terms of mean changes in hydroclimatology is of little relevance to the assessment of stress, and that the degree of impact varies inversely with the natural variability of the system. The example analyses have highlighted the relative differences in response for a fixed change in climate, and of course the actual impacts on any system will depend on the climate projections for that location and the management objectives of most interest.

Finally, we note that the assessment of hydrologic stress needs to assess the impacts of climate change separately from those of natural variability. This has implications for how the outputs of global and regional climate models are used. While the distribution of results from multi-model ensembles represents the epistemic uncertainty involved in projecting climate response to rising temperatures, ensembles from individual models based on different initial conditions are required to properly accommodate the aleatory uncertainty associated with natural variability. Change factors applied to baseline time series are widely used to assess the impacts of climate change. However, this approach is not well suited to assessing hydrologic stress, particularly in systems with long characteristic periods, as they necessarily assume that the future sequence of wet and dry periods is largely the same as in the baseline time series.

Acknowledgements Avril Horne gratefully acknowledges the funding provided by the Australian Research Council (LP170100598 and DE180100550).

\section{References}

Amrhein V, Greenland S, McShane B (2019) Retire statistical significance. Nature 567(March):7-9

Arnell NW, Gosling SN (2013) The impacts of climate change on river flow regimes at the global scale. J Hydrol 486:351-364 
Beyene T, Lettenmaier DP, Kabat P (2010) Hydrologic impacts of climate change on the Nile River Basin: implications of the 2007 IPCC scenarios. Clim Chang 100:433-461

Bond, N. R., Grigg, N., Roberts, J., McGinness, H., Nielsen, D., O’Brien, M., Overton, I., Pollino, C., Reid, J. R. W., and Stratford, D. (2018) Assessment of environmental flow scenarios using state-and-transition models. Freshwater Biology, (2017), 1-13

Brown C, Wilby RL (2012) An alternate approach to assessing climate risks. EOS Trans Am Geophys Union 92(41):92-94

Brown C, Ghile Y, Laverty M, Li K (2012) Decision scaling: linking bottom-up vulnerability analysis with climate projections in the water sector. Water Resour Res 48(9):WR09537

Chapman S, Mustin K, Renwick AR, Segan DB (2014) Publishing trends on climate change vulnerability in the conservation literature reveal a predominant focus on direct impacts and long time-scales. Divers Distrib 20: $1221-1228$

Döll P (2009) Vulnerability to the impact of climate change on renewable groundwater resources: a global-scale assessment. Environ Res Lett 4(3):035006

Döll P, Zhang J (2010) Impact of climate change on freshwater ecosystems: a global-scale analysis of ecologically relevant river flow alterations. Hydrol Earth Syst Sci 14(5):783-799

Ekström M, Grose MR, Whetton PH (2015) An appraisal of downscaling methods used in climate change research. Wiley Interdiscip Rev Clim Chang 6(3):301-319

Ekström M, Gutmann ED, Wilby RL, Tye MR, Kirono DGC (2018) Robustness of hydroclimate metrics for climate change impact research. Wiley Interdiscip Rev Water 5(4):e1288

Eyring V, Bony S, Meehl GA, Senior C, Stevens B, Stouffer RJ, Taylor KE (2016) Overview of the Coupled Model Intercomparison Project Phase 6 (CMIP6) experimental design and organisation. Geosci Model Dev Discuss 8(12):10539-10583

Fay PA, Guntenspergen GR, Olker JH, Johnson WC (2016) Climate change impacts on freshwater wetland hydrology and vegetation cover cycling along a regional aridity gradient. Ecosphere 7:10

Field, C.B., Barros, V.R., Mach K.J., Mastrandrea M.D., et al. (eds.) (2014) Climate change 2014: impacts, adaptation, and vulnerability. Part : global and sectoral aspects. Contribution of working group II to the fifth assessment report of the intergovernmental panel on climate change. Cambridge University Press, Cambridge, UK and New York, USA, $1132 \mathrm{pp}$.

Filipek S, Keith WE, Giese J (1987) The status of the instream flow issue in Arkansas, 422 1987. Proc Arkansas Acad Sci 41:43-48

Fowler HJ, Blenkinsop S, Tebaldi C (2007) Review: linking climate change modelling to impacts studies: recent advances in downscaling techniques for hydrological modelling. Int J Clim J Clim 27:1547-1578

Fu G, Charles SP, Chiew FHS, Teng J, Zheng H, Frost AJ, Liu W, Kirshner S (2013) Modelling runoff with statistically downscaled daily site, gridded and catchment rainfall series. J Hydrol 492:254-265

Füssel HM, Klein RJT (2006) Climate change vulnerability assessments: an evolution of conceptual thinking. Clim Chang 75(3):301-329

Giorgi F, Gutowski WJ (2015) Regional dynamical downscaling and the CORDEX initiative. Annu Rev Environ Resour 40(1):467-490

Gleckler PJ, Taylor KE, Doutriaux C (2008) Performance metrics for climate models. J Geophys Res 113: D06104. https://doi.org/10.1029/2007JD008972

Gosling SN, Zaherpour JJ, Mount NJ, Hattermann FF, Dankers R, Arheimer B, Breuer L, Ding J, Haddeland I, Kumar R, Kundu D, Liu J, van Griensven A, Veldkamp TIE, Vetter T, Wang X, Zhang X (2016) A comparison of changes in river runoff from multiple global and catchment-scale hydrological models under global warming scenarios of $1^{\circ} \mathrm{C}, 2^{\circ} \mathrm{C}$ and $3^{\circ} \mathrm{C}$. Clim Chang: $1-19$

Hart A (2001) Mann-Whitney test is not just a test of medians: difference in spread can be important. BMJ (formerly the British Medical Journal) 323:391-393

Hewitt C, Buontempo C, Newton P (2013) Using climate predictions to better serve society's needs. Eos 94(11): 105-107

Hijmans RJ, Cameron SE, Parra JL, Jones PG, Jarvis A (2005) Very high resolution interpolated climate surfaces for global land areas. Int J Climatol 25(15):1965-1978

Horne, A., Nathan, R., Poff, N.L., Bond, N., Webb, A. (submitted) Modelling flow-ecology responses in the Anthropocene: challenges for sustainable riverine management. Bioscience

Jackson J. and Cardenas-Lailhacar C. (2010) Economic feasibility of hydropower systems: a decision support system program. Proc. $8^{\text {th }}$ Latin American and Caribbean Conference for Engineering and Technology, June 2010, Arequipa, Peru

Jiménez-Cisneros, B.E., T. Oki, N.W. Arnell, G. Benito, J.G. Cogley, P. Döll, T. Jiang, and S.S. Mwakalila (2014) Freshwater resources. In: Climate change 2014: impacts, adaptation, and vulnerability. Part A: global and sectoral aspects. Contribution of working group II to the fifth assessment report of the intergovernmental 
panel on climate change. Field, C.B. et al (eds). Cambridge University Press, Cambridge, United Kingdom and New York, NY, USA, pp. 229-269

Klein-Tank, A.M.G., Zwiers, F.W., Zhang, X. (2009) Guidelines on analysis of extremes in a changing climate in support of informed decisions for adaptation, Climate Data and Monitoring, WCDMP-No 72, World Meteorological Organization

Mantyka-pringle CS, Martin TG, Moffatt DB, Linke S, Rhodes JR (2014) Understanding and predicting the combined effects of climate change and land-use change on freshwater macroinvertebrates and fish. J Appl Ecol 51:572-581

Markovic D, Carrizo SF, Karcher O, Walz A, David JW (2017) Vulnerability of European freshwater catchments to climate change. Glob Chang Biol 23:3567-3580

McMahon, T.A. and Mein, R.G. (1986) River and reservoir yield. Water Resources Publications, 368pp

McMahon TA, Vogel R, Peel M, Pegram G (2007) Global streamflows-part 1: characteristics of annual streamflows. J Hydrol 347:243-259

Peel MC, McMahon TA, Finlayson BL (2010) Vegetation impact on mean annual evapotranspiration at a global catchment scale. Water Resour Res 46(9):W09508

Peel MC, Srikanthan R, McMahon TA, Karoly DJ (2015) Approximating uncertainty of annual runoff and reservoir yield using stochastic replicates of global climate model data. Hydrol Earth Syst Sci 19:1615-1639

Perkins SE, Pitman AJ, Holbrook NJ, McAneney J (2007) Evaluation of the AR4 climate models' simulated daily maximum temperature, minimum temperature, and precipitation over Australia using probability density functions. J Clim 20:4356-4376

Poff NL, Richter BD, Arthington AH, Bunn SE, Naiman RJ, Kendy E, Acremen M, Apse C, Bledsoe BP, Freeman MC, Henriksen J, Jacobson RB, Kennen JG, Merritt DM, O’Keeffe JH, Olden JD, Rogers K, Tharme RE, Warner A (2010) The ecological limits of hydrologic alteration (ELOHA): a new framework for developing regional environmental flow standards. Freshw Biol 55:147-170

Prudhomme C, Wilby RL, Crooks S, Kay AL, Reynard NS (2010) Scenario-neutral approach to climate change impact studies: application to flood risk. J Hydrol 390:198-209

Roman CE, Lynch AH, Dominey-Howes D (2011) What is the goal? Framing the climate change adaptation question through a problem-oriented approach. Weather, Climate, and Society 3(1):16-30

Rössler, O., Fischer, A. M., Huebener, H., Maraun, D., Benestad, R. E., Christodoulides, P., ... Vlachogiannis, D. (2017): Challenges to link climate change data provision and user needs - perspective from the COST-action VALUE. Int J Climatol

Schewe J, Heinke J, Gerten D, Haddeland I, Arnell NW, Clark DB, Dankers R, Eisner S, Fekete B, ColónGonzález FJ, Gosling SN, Kim H, Liu X, Masaki Y, Portmann FT, Satoh Y, Stacke T, Tang Q, Wada Y, Wisser D, Albrecht T, Frieler K, Piontek F, Warszawski L, Kabat P (2014) Multi-model assessment of water scarcity under climate change. Proc Natl Acad Sci U S A 111(9):3245-3250

Seneviratne, S.I., N. Nicholls, D. Easterling, C.M. Goodess, S. Kanae, J. Kossin, Y. Luo, J. Marengo, K. McInnes, M. Rahimi, M. Reichstein, A. Sorteberg, C. Vera, and X. Zhang, 2012: Changes in climate extremes and their impacts on the natural physical environment. In: Managing the risks of extreme events and disasters to advance climate change adaptation. A special report of Working Groups I and II of the Intergovernmental Panel on Climate Change Field, C.B. et al (eds.). Cambridge University Press, Cambridge, UK, and New York, USA, pp. 109-230

Shepherd TG, Boyd E, Calel RA, Chapman SC, Dima-West IM, Fowler HJ et al (2018) Storylines: an alternative approach to representing uncertainty in physical aspects of climate change. Clim Chang 151(3-4):555-571

Sivakumar B, Singh VP (2012) Hydrologic system complexity and nonlinear dynamic concepts for a catchment classification framework. Hydrol Earth Syst Sci 16:4119-4131

Swart RJ, de Bruin K, Dhenain S, Dubois G, Groot A, von der Forst E (2017) Developing climate information portals with users: promises and pitfalls. Climate Services 6:12-22

Taylor KE, Stouffer RJ, Meehl GA (2012) An overview of CMIP5 and the experiment design. Bull Am Meteorol Soc 93:485-498

Teutschbein C, Wetterhall F, Seibert J (2011) Evaluation of different downscaling techniques for hydrological climate-change impact studies at the catchment scale. Clim Dyn 37(2087-2105):2011

Van Vliet MTH, Ludwig F, Kabat P (2013) Global streamflow and thermal habitats of freshwater fishes under climate change. Clim Chang 121:739-754

Vorosmarty G, Salisbury L (2000) Global water resources: vulnerability from climate change and population growth. Science 289(5477):284-288

Wang J, Nathan R, Horne A, Peel MC, Wei Y, Langford J (2017) Evaluating four downscaling methods for assessment of climate change impact on ecological indicators. Environ Model Softw 96:68-82

Wang QJ, Horne A, Nathan R, Peel M, Neave I (2018a) Vulnerability of ecological condition to the sequencing of wet and dry spells prior to and during the Murray Darling Basin millennium drought. J Water Resour Planning and Mngt 144(8):04018049

620 
Wang J, Nathan R, Horne A (2018b) Assessing the impact of climate change on environmental outcomes in the context of natural climate variability. J Water Resour Plan Manag 144(12)

Yeager SG, Danabasoglu G, Rosenbloom NA, Strand W, Bates SC, Meehl GA et al (2018) Predicting near-term changes in the earth system: a large ensemble of initialized decadal prediction simulations using the community earth system model. Bull Am Meteorol Soc 99(9):1867-1886

Zhao T, Bennett JC, Wang QJ, Schepen A, Wood AW, Robertson DE, Ramos MH (2017) How suitable is quantile mapping for postprocessing GCM precipitation forecasts. J Clim 30(9):3185-3196

Zheng H, Chiew FHS, Charles S, Podger G (2018) Future climate and runoff projections across South Asia from CMIP5 global climate models and hydrological modelling. J Hydrol: Reg Stud 18:92-109

Zomer RJ, Trabucco A, Bossio DA, van Straaten O, Verchot LV (2008) Climate change mitigation: a spatial analysis of global land suitability for clean development mechanism afforestation and reforestation. Agric Ecosyst Envir 126:67-80

Publisher's note Springer Nature remains neutral with regard to jurisdictional claims in published maps and 693 institutional affiliations. 